\title{
How Well Does Employment Predict Output?
}

\author{
Kevin L. Kliesen
}

Economists, policymakers, and financial market analysts typically pay close attention to aggregate employment trends because employment is thought to be an important indicator of macroeconomic conditions. One difficulty is that there are two separate surveys of employment, which can diverge widely from one another, as the previous and current economic expansions demonstrate. The conventional wisdom is that, for assessing economic conditions, the survey that counts the number of jobs (establishment survey) is preferable to the survey that counts the number of people employed (household survey). However, results from a one-quarter-ahead forecasting exercise presented in this paper suggest that analysts should question whether employment is a useful indicator for predicting output growth. (JEL C53, E24)

Federal Reserve Bank of St. Louis Review, September/October 2007, 89(5), pp. 433-46.

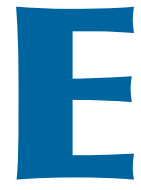

ach month, the Bureau of Labor Statistics (BLS) publishes the Employment Situation, a comprehensive report of key labor market statistics derived from separate surveys of nonagricultural business establishments (including government) and private households. Labor market conditions are among the most closely watched of all sources of economic statistics because they are, collectively, thought to be a comprehensive indicator of economic activity. In addition, many of its components (for example, hours worked) are used in the construction of other key economic statistics, such as the Federal Reserve Board's index of industrial production (IP). As a result, policymakers and economic analysts monitor labor market conditions carefully to help them gauge the evolving strength or weakness in the pace of aggregate economic activity over the nearterm. In fact, policymakers and analysts use these data, ideally, to more accurately predict economic activity and avoid forecast surprises, which have been shown to significantly affect the behavior of financial markets. ${ }^{1}$

This article will first briefly discuss the two surveys that the BLS uses to measure employment and then discuss the different patterns in employment growth registered by each measure over the past two business cycles. The article will provide some evidence, with a one-quarter-ahead pseudo out-of-sample forecasting exercise, that neither measure of employment is a reliable predictor of the growth of IP or real gross domestic product (GDP).

\section{TWO EMPLOYMENT SURVEYS}

One difficulty that confronts economic analysts who use employment to help predict the growth of real GDP is which employment measure to use. The BLS publishes two measures of employment that receive the most attention.

\footnotetext{
1 See Kliesen and Schmid (2004 and 2006).
}

Kevin L. Kliesen is an associate economist at the Federal Reserve Bank of St. Louis. The author thanks Bill Emmons, Mike McCracken, and Dan Thornton for helpful suggestions and Joshua A. Byrge for research assistance.

(C) 2007, The Federal Reserve Bank of St. Louis. Articles may be reprinted, reproduced, published, distributed, displayed, and transmitted in their entirety if copyright notice, author name(s), and full citation are included. Abstracts, synopses, and other derivative works may be made only with prior written permission of the Federal Reserve Bank of St. Louis. 


\section{Table 1}

\section{Differences Between the CES and the CPS}

\section{CES}

- Monthly sample survey of 160,000 businesses and government agencies; firms of all sizes are included

- Designed to measure employment, hours, and earnings with significant industrial and geographic detail

- Reference period is the pay period (could be weekly, biweekly, monthly, and so forth) that includes the 12th of the month

- Employees of all ages are included

- Employment measure reflects the number of nonfarm payroll jobs

- Multiple jobholders are counted for each payroll job

- Self-employed persons are excluded

- Agriculture sector is excluded

- Private household workers (nannies, housekeepers, and the like) are excluded

- Unpaid family workers (persons working without formal pay in their family's business are excluded

- Workers on leave without pay throughout the reference period are excluded

\section{CPS}

- Monthly sample survey of approximately 60,000 households

- Designed to measure employment and unemployment with significant demographic detail

- Reference period is the week that includes the 12th of the month

- Only workers aged 16 and older are included

- Employment measure reflects the number of employed persons

- Multiple jobholders are counted once

- Self-employed persons are included

- Agriculture sector is included

- Private household workers are included

- Unpaid family workers are included

- Workers on leave without pay throughout the reference period are included

NOTE: Reprinted from Bowler and Morisi (2006, p. 24) with permission.

One is nonfarm payroll employment. This measure is taken from the Current Employment Statistics survey (CES), which is a survey of about 160,000 businesses and government agencies (establishments) that cover about a third of all nonfarm payroll workers. The other measure is civilian employment, which is taken from the Current Population Survey (CPS). The CPS is a survey of about 60,000 households, of roughly 110 million households in the United States. It is often referred to as the household survey or household employment.

These two series are reported each month in the Employment Situation, which is typically released on the first Friday of each month by the BLS. According to the BLS, the CES is designed chiefly to track changes such as jobs and hours, whereas the CPS is designed chiefly to track changes in rates, such as the unemployment rate or the labor force participation rate. ${ }^{2}$
As seen in Table 1, there are several differences between the two surveys. For example, the CPS (household survey) includes agricultural and unincorporated self-employed workers, as well as those who are on unpaid absence; the CES (establishment survey) includes none of these. ${ }^{3}$ Also, the CES includes multiple jobholders and workers of all ages, whereas the CPS counts an employed person only once and only those who are at least 16 years old. Finally, each year the CES estimates are benchmarked to the actual employment levels reported by the state unemployment

\footnotetext{
2 Bowler and Morisi (2006).

3 There are two measures of self-employment: incorporated and unincorporated. Unincorporated self-employed individuals have the status of unpaid family workers-that is, they are assumed not to be paid employees. These are reported in the CPS only. However, the incorporated self-employed are assumed to be paid employees of their own corporations and, hence, are counted in the CES.
} 
insurance records. ${ }^{4}$ Typically, the benchmark revisions are relatively small. According to the BLS, the benchmark revisions averaged \pm 0.2 percent from 1996 to 2005. However, the 2006 benchmark revision was unusually large, measuring 0.6 percent. ${ }^{5}$ In contrast, the CPS estimates are derived from annual estimates of the civilian noninstitutional population provided by the Bureau of the Census. ${ }^{6}$

Although the coverage of the labor market is broader in the household survey, most economists probably place more emphasis on the establishment survey because it is constructed from a much larger sample and is less volatile than the household survey. Of course, this assumes that each survey is a statistically representative sampling of the population; typically, a larger sample of the population produces more accurate estimates than a smaller sample of the population.

To see why the CES might be a superior timeseries measure, consider the following. The BLS survey of businesses and government agencies encompasses about 400,000 individual worksites, which covers about a third of all workers. ${ }^{7}$ Thus, the BLS is implicitly surveying a little more than 45 million workers. By contrast, the CPS encompasses about 60,000 households (or about 76,000 workers). This represents only 0.05 percent of total households and 0.2 percent of those implicitly surveyed by the CES. ${ }^{8,9}$

\footnotetext{
4 These data are reported every three months in the Quarterly Census of Employment and Wages, also known as the ES-202. See www.bls.gov/cew/home.htm.

5 See www.bls.gov/web/cesbmart.htm.

6 The population controls for the CPS are based on the decennial census. Intercensal population estimates from the Census Bureau are based on births, deaths, and estimates of net internal immigration.

7 See BLS Handbook of Methods (Chapter 2); www.bls.gov/opub/hom/homch2_a.htm.

8 According to Bowler and Morisi (2006), the monthly CPS sampling error is four times larger than that of the CES.

9 The CPS surveys about 60,000 households. This represents only 0.05 percent of total households. Viewed another way, there are 1.26 employees per household, which represents nearly 76,000 persons surveyed. This sample is less than 0.2 percent of those implicitly surveyed by the CES.
}

\section{Reconciling the Two Employment Measures}

Despite the marked differences in their structural characteristics, the two series have increased at comparable rates since their inception. From 1948 to 2006, the CES has grown at a 1.6 percent annual rate, whereas the CPS has grown at a 1.9 percent annual rate. At shorter time horizons, though, the growth rates have diverged considerably. For example, Figure 1 shows that peak and trough growth rates of the CES are generally larger (in absolute terms) than those of the CPS. To help reconcile divergences, the BLS creates an adjusted series that attempts to net out, as much as possible, the methodological differences between the two surveys.

Each month, the BLS computes an employment measure from the CPS that is designed to be conceptually equivalent to that of the CES. This adjusted measure has been published on a monthly basis since January 1994, when there was a major redesign of the CPS. ${ }^{10}$ To make the CPS measure conceptually equivalent to the CES measure, as seen in Table 2, the BLS subtracts the following employment categories of the CES that are outside of the scope of the CPS: (i) agriculture, (ii) nonagricultural self-employment, (iii) nonagricultural unpaid family workers, (iv) private household workers, and (v) unpaid absences. To this adjustment, the BLS also adds the number of workers with multiple jobs. ${ }^{11}$ Table 2 shows, as of 2006, that CES employment totaled 136.935 million and CPS-adjusted employment totaled 139.415 million-an unexplained difference of 2.48 million. (In December 2005, it was 1.67 million.)

Figure 2 shows the evolution of the CES-CPS discrepancy during the past two business cycles. Panel A shows employment trends during the 1990s expansion, and panel B shows employment trends during the current business expansion. Each employment series is indexed to equal 1 during the trough months of the recessions in

\footnotetext{
${ }^{10}$ See Polivka and Miller (1998).

11 The number of multiple jobholders are those 16 and older with secondary jobs.
} 


\section{Figure 1}

\section{Employment Growth, 1950 to 2006}

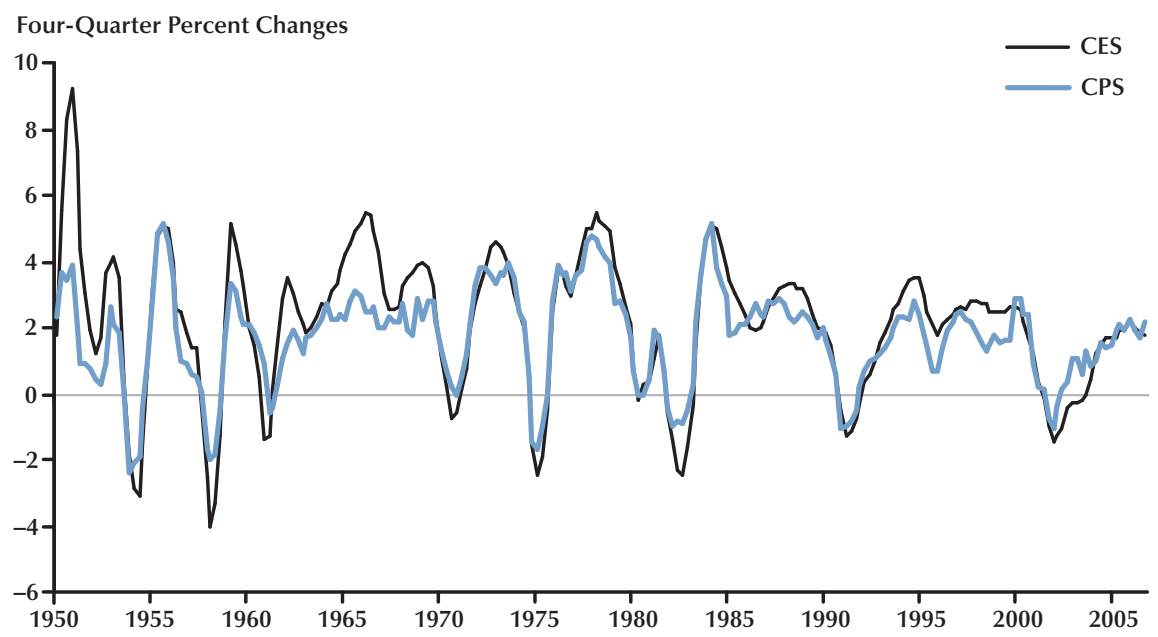

SOURCE: BLS and author's calculations.

\section{Table 2}

\section{CES-CPS Reconciliation Table (in thousands)}

\section{Employment}

Payroll jobs

Household employment*

Less: Agriculture

Nonagricultural self-employed

Nonagricultural unpaid family workers

Private household workers

Unpaid absences

Total

Plus: Multiple jobholders ${ }^{\dagger}$

Adjusted household employment*

Adjusted household employment less payroll jobs

Addenda: Nonagricultural wage and salary workers

December 2005

December 2006

Percent change

$\begin{array}{rrr}135,041 & 136,935 & 1.4 \\ 142,918 & 146,081 & 2.2 \\ 1,942 & 2,079 & 7.1 \\ 9,294 & 9,751 & 4.9 \\ 66 & 99 & 50.0 \\ 782 & 722 & -7.7 \\ 1,412 & 1,547 & 9.6 \\ 13,496 & 14,198 & 5.2 \\ 7,289 & 7,533 & 3.3 \\ 136,711 & 139,415 & 2.0 \\ 1,670 & 2,480 & 48.5 \\ 130,755 & 132,901 & 1.6\end{array}$

NOTE: *The changes in household employment and adjusted household employment have been adjusted to account for the introduction of new population controls in January 2006. ${ }^{\dagger}$ Multiple jobholders who are nonagricultural wage and salary workers on their primary job. Totals and changes in household employment series are based on unrounded numbers. Data are not seasonally adjusted, and the published numbers are those prior to the March 2006 benchmark revisions published in February 2007.

SOURCE: BLS. 
Figure 2

\section{Establishment and Household Employment During the 1991-2001 and Current} Business Expansion

A. January 1990 to December 2000 (Index, March $1991=1.0$ )

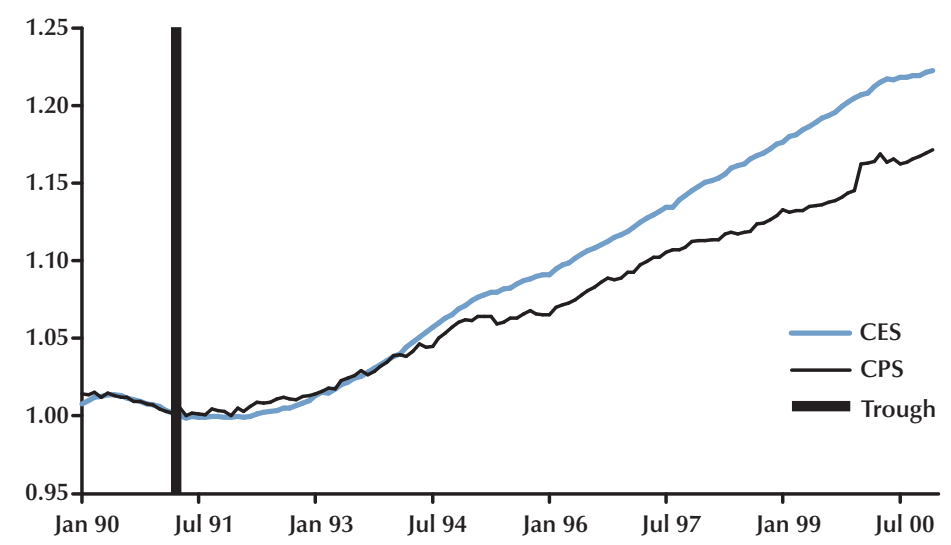

B. January 2001 to December 2006 (Index, November 2001 = 1.0)

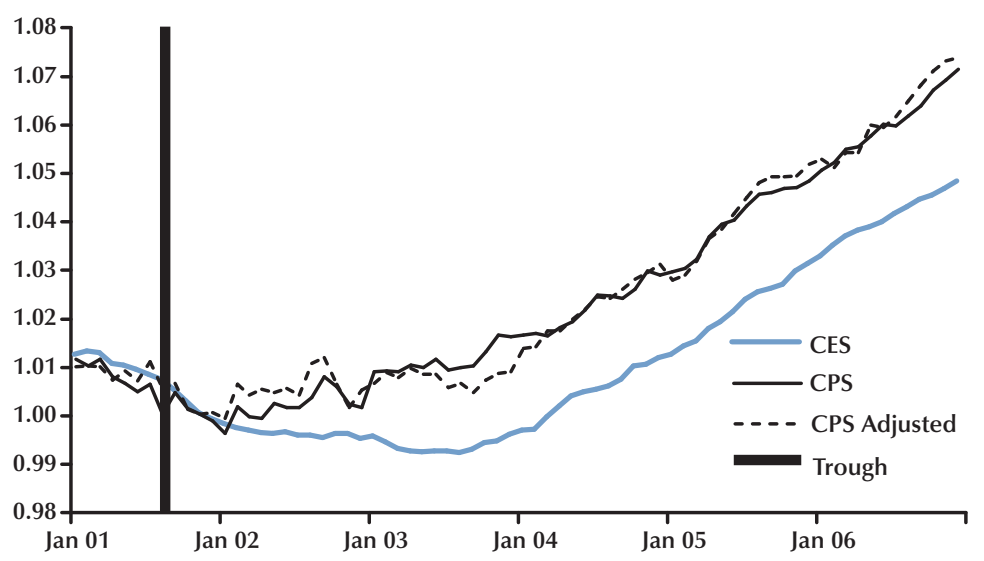

NOTE: Data are seasonally adjusted by the BLS and reflect the March 2006 benchmark revision published in February 2007. Vertical lines indicate the month declared to be the end of the recession (trough).

SOURCE: BLS and author's calculations. 
1990-91 (July 1990) and 2001 (November 2001), respectively. The CES and CPS measures are shown in each panel, but panel B also includes the CPS-adjusted measure. Recall that this series has been available only since January $1994 .^{12}$

Although the CPS growth and CPS-adjusted rates have kept up with the CES growth rate overall since 1994, the CES and CPS measures have moved in distinct patterns since that year (see Figure 2A). ${ }^{13}$ From January 1994 to March 2001, increases in payroll employment (CES) averaged about 233,000 per month, while they averaged only about 184,000 per month for household employment (CPS). From November 2001 to December 2006, the opposite occurred: Household employment increased by an average of about 159,000 per month, while payroll employment increased by an average of only 103,000 per month. Panel B also shows that the CPS-adjusted measure has increased in line with total household employment, although there has been some slight widening between the two measures in 2006. From November 2001 to December 2006, the CPS-adjusted measure increased by 155,000 per month, which is virtually identical to the average increase in the unadjusted CPS.

\section{Analysis in the Literature}

Numerous studies have attempted to explain the discrepancies between the two growth rates of the two main employment series during these two periods. Many researchers have focused on structural changes in the economy, such as innovations in the production and distribution of manufactured goods, or increases in trend labor productivity growth rates: See Kahn (1993), Schreft and Singh (2003), and Groshen and Potter (2003). In this vein, Koenders and Rogerson (2005) argue that slow employment growth tends to follow long expansions-such as those in 1982-90 and 1991-2001-because firms postpone structural changes during periods of relatively strong growth.

\footnotetext{
12 The CPS-adjusted series is adjusted to smooth out the discrete jumps in population that occurred because of revisions in January 2000, 2003, 2004, 2005, and 2006.

${ }^{13}$ From January 1994 to December 2006, the average monthly gains are as follows: CES, 159,000; CPS, 155,000; CPS adjusted, 159,000.
}

One potential difficulty with these explanations, as Aaronson, Rissman, and Sullivan (2004) point out, is that structural change is a regular feature of a dynamic economy that is continually subject to waves of creative destruction.

Bowler and Morisi (2006) take a somewhat different approach by reviewing several possible explanations tied to methodological differences between the two employment surveys. They found that the population undercount explained roughly one-third of the 4.5 million cumulative gap between the CES and CPS measures of employment that arose in the late 1990s. ${ }^{14}$ This is consistent with an earlier finding by Juhn and Potter (1999), who argued that the widening gap between the CES and CPS in the 1990s was likely due to an underestimate of the working-age population. Recall that employment estimates in the CPS are derived from estimates of the noninstitutional population that are provided by the Bureau of the Census. In January 2003, the BLS incorporated into the CPS the decennial census population estimate. This introduction resulted in revisions to the population controls, and thus the CPS data, from January 2000 through December 2002. ${ }^{15} \mathrm{~A}$ second major revision occurred in January 2003 because of the annual intercensal population adjustment. ${ }^{16}$

Bowler and Morisi also reviewed other sources of systematic error, such as workers with multiple jobs, military personnel with secondary civilian jobs, foreign commuters, and differences in the reference periods between the two surveys. None of these factors, they argued, could explain the 1990s discrepancy with any significance. Regarding developments since 2001-that is, the relatively faster growth of household employment-they argue that the causes of this discrepancy are also not fully known. Two possibilities are increased job turnover and potential inaccuracies in the population controls. An earlier BLS paper by Nardone et al. (2003) argued that undoc-

\footnotetext{
${ }^{14}$ Their sample period was 1994-2000. The 4.5 million gap does not include the population revisions associated with the introduction of the Census 2000 population controls in January 2003.

${ }^{15}$ See Bowler et al. (2003).

${ }^{16}$ See footnote 4 .
} 


\section{Table 3}

\section{Correlation Between Various Measures of Employment and Output Growth (one-quarter percent changes)}

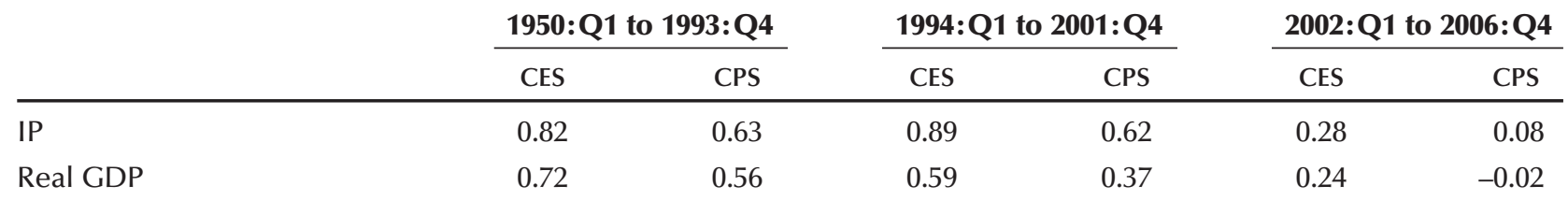

SOURCE: Author's calculations.

umented immigration may also bias population controls and thus also the estimates of CPS employment. The divergent pattern of employment growth in the current expansion potentially presents another difficulty for economic analysts who use employment as a predictor of near-term economic activity.

\section{GAUGING THE INFORMATION CONTENT OF THE EMPLOYMENT MEASURES}

In the short term, changes in the demand for goods and services are assumed to cause changes in the demand for labor. But because the employment statistics are reported in advance of the primary measure of aggregate output (real GDP), policymakers tend to view them as a gauge for future changes in output. However, predicting output based solely on changes in labor input is complicated by changes in labor productivity.

A key question among economic analysts during the 1990s was whether the faster growth of CES employment was a more accurate portrayal of underlying trends in employment than was household employment. With the converse being true since the 2001 recession, a parallel question is whether the relatively faster growth of household employment is a truer measure of the economy's employment growth and thus its near-term growth of economic activity. If so, should economic analysts pay more attention to CPS employment to predict real GDP growth? Or should they continue to rely more on the CES? The conventional wisdom, as recently expressed by Federal
Reserve Chairman Ben Bernanke (2003), is that the CES is the preferred measure:

[B] ecause of the larger sample used in the payroll survey and because of possible problems with the population estimates used to scale the household survey, somewhat greater reliance should probably be placed on the payroll survey.

Table 3 provides a preliminary assessment of whether economic analysts should continue to rely more on the CES or put more weight on the CPS. Table 3 shows simple correlations between the annualized one-quarter growth rate of two measures of economic activity-IP and real GDPand the two primary measures of employment plotted in panel A of Figure 2-CES and CPS. The table lists the correlations over three separate periods: (i) 1950:Q1-1993:Q4; (ii) 1994:Q12001:Q4; and (iii) 2002:Q1-2006:Q4. The 1994 breakpoint is chosen because, as noted earlier, the CPS was changed in several important ways in that year; the 2001 break point was chosen to be consistent with the analysis presented earlier.

As seen in Table 3, correlations between the growth of employment and IP are invariably stronger than those between the growth of employment and real GDP. This result holds across all three periods and for each employment series. This finding seems surprising given that IP measures the output of the goods-producing sector, which is only about 35 percent of real GDP. ${ }^{17}$ It

\footnotetext{
${ }^{17}$ This share increases to 45 percent if structures are added to goods production. In nominal terms, the goods share is 31 percent and the sum of goods and structures is 42 percent.
} 
is also the case that the correlation coefficients for the CES series are larger than those for the CPS series. This is consistent with the conventional wisdom noted earlier that most economists follow: The CES is as a better measure of employment conditions.

A second finding from Table 3 is that the correlations between employment and output have changed significantly over time. ${ }^{18}$ For example, the correlation coefficient between the growth of CES employment and IP increased from 0.82 in the 1950-93 period to 0.89 in the 1994-2001 period. This result may reflect both the faster growth of CES employment during the 1990s and the strong gains in labor productivity and equity prices that helped spur a boom in business capital spending. Since 2001, the correlation between the growth of CES employment and IP has dropped to 0.28. A similar finding is found for real GDP growth and employment. Over time, the correlation between the growth of CES employment and real GDP declined from 0.72 (1950-93) to 0.59 (1994-2001) to 0.24 (2002-06). A similar result was found for the correlation between the growth of CPS employment and real GDP growth. In fact, the CPS-real GDP correlation during the current period (2002-06) is now negative. This seems surprising given that the growth of CPS employment has been stronger than CES employment over this period.

The finding that the correlation between the growth of household employment and real GDP has decreased over time contrasts with the results shown in Perry (2005). He provides evidence that, since 1994, household employment has been a better measure of aggregate employment than payroll employment when predicting real GDP growth or growth of nonfarm business output (a subset of GDP). Perry concludes that both measures include important information and that an economic analyst might benefit from adopting

\footnotetext{
18 The correlations in Table 3 are somewhat sensitive to the end points, depending on whether the 2001 recession is moved to the second or third period. For example, choosing 2000:Q4 as the end point of the second period lowers the correlations between employment and output in the second period while raising them in the third period. However, this does not change the overall conclusion that the correlations between employment and output growth have generally weakened over time.
}

the simple rule of thumb of averaging the monthly changes in the two series. However, the correlations presented in Table 3 suggest that economic analysts should pay less attention to the CPS relative to the CES (conventional wisdom). In the next section, I formally assess the validity of this conventional wisdom.

\section{FORECASTING OUTPUT USING MEASURES OF EMPLOYMENT}

Expectations about the state of the U.S. economy matter tremendously to policymakers. Accordingly, the Federal Open Market Committee (FOMC) closely monitors the incoming flow of economic data to see whether its information content is consistent with the prevailing forecast for inflation and key indicators of real activity. Chairman Bernanke and other senior Federal Reserve officials have called this a "datadependent policy." 19 One of the most important data series that shapes the FOMC's view is the monthly change in employment. The purpose of this section is to assess whether employment changes are a good predictor of real output growth over the following quarter.

For this analysis, I use two measures of output and six measures of employment, with data measured at a quarterly frequency. The two measures of output are real GDP and IP, the same measures used in Table 3. There are six measures of employment:

- nonfarm payroll employment (CES);

- civilian employment (CPS);

- civilian wage and salary workers (CPS W\&S);

- the Perry (2005) rule-of-thumb series, which measures the average change of the CES and CPS (CES-CPS AVG);

- nonfarm payroll employment plus the measure of self-employed workers (CES + SE);

- the CPS less the measure of self-employed workers from the CPS (CPS - SE).

\footnotetext{
${ }^{19}$ See Poole (2006).
} 


\section{Table 4}

Summary Statistics for Output and Employment (one-quarter percent changes, not annualized)

\begin{tabular}{|c|c|c|c|c|c|c|c|c|}
\hline & Real GDP & IP & CES & CPS & CPS W\&S & $\begin{array}{c}\text { CES-CPS } \\
\text { AVG }\end{array}$ & $\mathrm{CES}+\mathrm{SE}$ & CPS - SE \\
\hline \multicolumn{9}{|l|}{ 1950:Q1 to $1993:$ Q4 } \\
\hline Average & 0.89 & 0.94 & 0.54 & 0.42 & 0.52 & 0.48 & 0.51 & 0.45 \\
\hline Standard deviation & 1.09 & 2.24 & 0.70 & 0.56 & 0.63 & 0.59 & 0.65 & 0.61 \\
\hline \multicolumn{9}{|l|}{ 1994:Q1 to 2006:Q4 } \\
\hline Average & 0.80 & 0.83 & 0.39 & 0.36 & 0.40 & 0.37 & 0.37 & 0.37 \\
\hline Standard deviation & 0.48 & 0.93 & 0.35 & 0.36 & 0.41 & 0.31 & 0.35 & 0.36 \\
\hline
\end{tabular}

SOURCE: Author's calculations.

The rationale for including the final two measures stems from the fact that the growth of self-employment has been considerably stronger in the period following the 2001 recession. ${ }^{20}$ From November 2001 through December 2006, self-employment increased by 11 percent, while total CPS employment increased by 7.1 percent. Hence, self-employment may be one potential explanation for the current growth gap between the CES and the CPS. Finally, I do not use the BLS's CPS series that is conceptually equivalent to the CES because that series is not available before the first quarter of 1994 .

Table 4 provides some basic statistics for the economic series that will be used in the empirical analysis. I look at two periods: 1950:Q1-1993:Q4 and 1994:Q1-2006:Q4. Table 4 offers a few key findings. First, average growth of real GDP and IP are approximately equal in each period. Second, volatility declined by more than half for GDP growth and by slightly more than that for IP growth in the second period. Third, the growth of CES employment is larger than the growth of CPS employment, but the gap narrowed by threefourths in the second period. Finally, volatility has also declined for employment growth, though less than it has for output. Moreover, in the second period, CES and CPS employment volatility are

${ }^{20}$ From 1948 to 1966, self-employment averaged 9.5 percent of civilian employment, but it has held fairly steady since the mid1960s, fluctuating between 6.5 and 7.5 percent since 1967 . approximately equal, which contrasts with the earlier period. Although, the differences in volatility among the employment series are small, the CES-CPS average is the least volatile.

I use the following autoregressive model (AR), with four lags of the dependent variable, as the benchmark one-quarter-ahead forecast for the quarterly change in output:

$$
X_{t}=\alpha_{t}+\sum_{i=1}^{4} \beta_{i} X_{t-i}+\mu_{t},
$$

where $X_{t}$ is the log change (annualized) in real GDP or IP. To test whether adding information from employment produces a more accurate onequarter-ahead forecast than the benchmark model, I add, in six separate regressions, the log changes of employment described earlier. Finally, I consider two separate modifications to the benchmark model. In the first specification, I add the first lag of the quarterly log change (annualized) in employment, $Y_{t-1}$, to the baseline model:

$$
X_{t}=\alpha_{t}+\sum_{i=1}^{4} \beta_{i} X_{t-i}+\gamma Y_{t-1}+\mu_{t}
$$

In the second specification, I add (separately) the contemporaneous value of the quarterly log change (annualized) in employment, $Y_{t}$, to the baseline model:

$$
X_{t}=\alpha_{t}+\sum_{i=1}^{4} \beta_{i} X_{t-i}+\gamma Y_{t}+\mu_{t}
$$


This form of a nested, one-step-ahead forecast is common in the literature, where (1) is termed the restricted model and (2) and (3) are unrestricted models. ${ }^{21}$

Tables 5 and 6 show the root mean-squared errors (RMSE) from this one-step-ahead pseudo out-of-sample forecasting exercise for the restricted model and for both specifications of the unrestricted model. ${ }^{22}$ In both tables, the starting point for the estimation period is the first quarter of 1950. To see how the one-step-ahead pseudo out-of-sample forecasting exercise is conducted, consider Table 5. In this case, the out-of-sample forecast horizon is from 1994:Q1 to 2001:Q4. Thus, the model is estimated using data from 1950:Q1 to 1993:Q4. Next, the model forecasts the growth of real GDP in 1994:Q1 and uses either the lagged (specification (1)) or contemporaneous (specification (2)) growth of employment in 1994:Q1. To forecast the growth of real GDP in 1994:Q2, the model is run using actual data through 1994:Q1 and so forth for each quarter. In essence, the forecasting exercise tests whether knowing the quarterly change in employmenteither the contemporaneous change or its value in the previous quarter-is useful for predicting the growth rate of real GDP or IP. ${ }^{23}$ A similar exercise is repeated in Table 6, but the out-of-sample forecast horizon is from 2002:Q1 to 2006:Q4. RMSEs in Tables 5 and 6 , then, are the averages for the out-of-sample forecast period indicated for each model.

Tables 5 and 6 indicate that the RMSEs from the restricted and unrestricted models are always less for forecasts of real GDP than for IP. This perhaps reflects that (i) more than half of GDP is services output and (ii) goods output is more volatile than services output. Another key finding is that the RMSEs for the benchmark forecasts for IP and

\footnotetext{
${ }^{21}$ See Clark and McCracken (2001), who cite the seminal work of Meese and Rogoff (1983). See Stock and Watson (2003) for an application to forecasting inflation with asset prices.

22 The forecasts are termed "pseudo" because actual data are used to generate a one-step-ahead forecast that will be compared with the actual growth rate.

${ }^{23}$ The data in this article incorporate all previous revisions (currentvintage data). An interesting extension of this exercise would be a test of whether the results would change if real-time data were used.
}

real GDP growth are significantly lower in the latter period (Table 6) than in the earlier period (Table 5). This finding suggests that reduced volatility helps a forecaster produce more accurate (lower RMSEs) forecasts. ${ }^{24}$

A more interesting finding from the tables is that forecast accuracy in either period appears to depend significantly on whether the lagged or contemporaneous value of employment is used to forecast output. Table 5 suggests that adding the contemporaneous value of CES employment substantially lowers the RMSE in the earlier period but not in the latter period. For example, in the forecast period encompassing 1994:Q1-2001:Q4, adding CES employment lowers the RMSE for the IP forecast from 3.25 percent to 2.48 percent and for real GDP from 2.05 percent to 1.65 percent. Using the lagged value of the CES in the earlier period lowers the RMSE for real GDP only slightly (from 2.05 to 2.00), but it raises the RMSE slightly for IP (from 3.25 to 3.31 ). The remaining specifications of the unrestricted model in the earlier period uniformly produced higher RMSEs than the contemporaneous value of the CES.

In contrast, Table 6 shows the opposite finding. In the latter period (2002:Q1-2006:Q4), adding the lagged value of the CES to the restricted model produces a lower RMSE, whereas using the contemporaneous value of the CES produces a higher RMSE. For example, using the lagged specification, adding the CES to the restricted model lowers the RMSE for IP from 2.78 to 2.50 percent; for real GDP, the RMSE declines from 1.61 to 1.54 percent. A similar-size RMSE is produced using either the CPS W\&S or the CES-CPS AVG in the real GDP forecast in the lagged specification. The latter finding is consistent with Perry's (2005) results noted earlier. Adding the self-employed to the CES (CES + SE) produces a more accurate forecast than the contemporaneous value of the CES by itself; however, the result fails to hold when using the lagged values of employment in this period.

\footnotetext{
${ }^{24}$ This point is made by Stock and Watson (2005). They argue that RMSEs for inflation and output forecasts have been reduced since the mid-1980s because of the Great Moderation. Regarding the latter, see McConnell and Pérez-Quirós (2000) or Ahmed, Levin, and Wilson (2004).
} 


\section{Table 5}

One-Quarter-Ahead Forecast Errors (RMSEs), 1994:Q1 to 2001:Q4

\begin{tabular}{|c|c|c|c|c|}
\hline & \multicolumn{2}{|r|}{ IP } & \multicolumn{2}{|c|}{ Real GDP } \\
\hline & Lagged & Contemporaneous & Lagged & Contemporaneous \\
\hline \multicolumn{5}{|l|}{ Restricted model } \\
\hline $\mathrm{AR}(4)$ & 3.25 & 3.25 & 2.05 & 2.05 \\
\hline \multicolumn{5}{|c|}{ Unrestricted models } \\
\hline CES & 3.31 & 2.48 & 2.00 & 1.65 \\
\hline CPS & 3.24 & 3.33 & 2.01 & 2.18 \\
\hline CPS W\&S & 3.42 & 3.62 & 2.07 & 2.22 \\
\hline CES-CPS AVG & 3.27 & 2.94 & 1.99 & 1.90 \\
\hline $\mathrm{CES}+\mathrm{SE}$ & 3.27 & 2.85 & 1.91 & 1.97 \\
\hline CPS - SE & 3.27 & 3.14 & 2.06 & 1.97 \\
\hline
\end{tabular}

NOTE: CES, nonfarm payroll employment; CPS, civilian employment; CPS W\&S, civilian employment, nonfarm wage, and salary workers; CES-CPS AVG, average of civilian and nonfarm payroll employment; CES + SE, nonfarm payroll employment plus self employment; CPS - SE, civilian employment less self employment. First actual observation: 1950:Q1.

\section{Table 6}

One-Quarter-Ahead Forecast Errors (RMSEs), 2002:Q1 to 2006:Q4

\begin{tabular}{|c|c|c|c|c|}
\hline & \multicolumn{2}{|r|}{ IP } & \multicolumn{2}{|c|}{ Real GDP } \\
\hline & Lagged & Contemporaneous & Lagged & Contemporaneous \\
\hline \multicolumn{5}{|l|}{ Restricted model } \\
\hline $\mathrm{AR}(4)$ & 2.78 & 2.78 & 1.61 & 1.61 \\
\hline \multicolumn{5}{|c|}{ Unrestricted models } \\
\hline CES & 2.50 & 3.24 & 1.54 & 1.87 \\
\hline CPS & 2.75 & 3.02 & 1.57 & 1.81 \\
\hline CPS W\&S & 2.77 & 3.19 & 1.53 & 2.06 \\
\hline CES-CPS AVG & 2.56 & 2.74 & 1.54 & 1.77 \\
\hline $\mathrm{CES}+\mathrm{SE}$ & 2.55 & 2.96 & 1.61 & 1.75 \\
\hline CPS - SE & 2.73 & 3.08 & 1.56 & 1.91 \\
\hline
\end{tabular}

NOTE: See Table 5 for descriptions of the mnemonics. 
Table 7

Clark-McCracken Tests of Forecast Accuracy, 1994:Q1 to 2001:Q4

\begin{tabular}{lrcrcr} 
& \multicolumn{2}{c}{ IP } & & \multicolumn{2}{c}{ Real GDP } \\
\cline { 2 - 3 } \cline { 5 - 6 } & Lagged & Contemporaneous & & Lagged & Contemporaneous \\
\hline Unrestricted models & & & & \\
CES & -0.0004 & 0.0262 & & 0.0012 & 0.0182 \\
CPS & 0.0006 & 0.0095 & & 0.0010 & 0.0046 \\
CPS W\&S & -0.0002 & 0.0082 & & 0.0003 & 0.0058 \\
CES-CPS AVG & 0.0002 & 0.0191 & & 0.0015 & 0.0116 \\
CES + SE & 0.0000 & 0.0179 & & 0.0031 & 0.0084 \\
CPS - SE & 0.0002 & 0.0109 & & 0.0001 & 0.0084
\end{tabular}

$10 \%$ critical value: 0.473

NOTE: See Table 5 for descriptions of the mnemonics. In each case, the forecast from the unrestricted model is tested against the forecast from the restricted model. The null is that there is on difference between the two forecasts.

\section{Table 8}

Clark-McCracken Tests of Forecast Accuracy, 2002:Q1 to 2006:Q4

\begin{tabular}{llclcc} 
& \multicolumn{2}{c}{ IP } & & \multicolumn{2}{c}{ Real GDP } \\
\cline { 2 - 3 } \cline { 5 - 6 } & Lagged & Contemporaneous & & Lagged & Contemporaneous \\
\hline Unrestricted models & & & & \\
CES & 0.0070 & 0.0316 & & 0.0056 & 0.0146 \\
CPS & 0.0012 & 0.0038 & & 0.0018 & 0.0018 \\
CPS W\&S & 0.0025 & 0.0080 & & 0.0043 & 0.0021 \\
CES-CPS AVG & 0.0057 & 0.0244 & & 0.0044 & 0.0093 \\
CES + SE & 0.0059 & 0.0294 & & 0.0034 & 0.0140 \\
CPS - SE & 0.0016 & 0.0057 & & 0.0019 & 0.0018
\end{tabular}

$10 \%$ critical value: 0.335

NOTE: See Table 5 for descriptions of the mnemonics. In each case, the forecast from the unrestricted model is tested against the forecast from the restricted model. The null is that there is on difference between the two forecasts. 
Ultimately, the value of any forecast is its accuracy. A standard test of forecast accuracy is the nonparametric test proposed by Diebold and Mariano (1995). However, as Clark and McCracken (2001) point out, the Diebold and Mariano test is not appropriate for nested models like the one used in this paper. The reason is that the limiting distribution of the Diebold and Mariano test is not normal when the null hypothesis is equal predictive power (of the restricted and unrestricted test). ${ }^{25}$ Tables 7 and 8 show test statistics based on an alternative test proposed by Clark and McCracken (2005). In each case, the forecasts from the unrestricted models in Tables 5 and 6 are tested against the restricted model. The null hypothesis is that the two forecasts have the same predictive power.

Despite the sizable difference between the RMSEs of the restricted model and certain unrestricted models-especially the latter featuring the CES-the Clark-McCracken test statistics indicate that the information contained in quarterly changes in employment does not significantly improve upon the benchmark AR(4) forecast. This result holds for both periods and regardless of whether one uses the contemporaneous specification or the lagged specification. Accordingly, employment does not appear to be a statistically useful predictor of output growth in the following quarter, which seems contrary to the conventional wisdom.

\section{CONCLUSION}

Economists, policymakers, and financial market analysts typically pay close attention to aggregate employment trends, because employment is thought to be an important indicator of macroeconomic conditions. One difficulty is that there are two separate surveys of employment, and, moreover, these measures can diverge from one another in a significant fashion, as the previous and current economic expansions demonstrate. The conventional wisdom is that the employment survey that counts the number of

\footnotetext{
${ }^{25}$ Also see McGuckin, Ozyildirim, and Zarnowitz (2007).
}

jobs (establishment survey) is preferable to the survey that counts the number of people employed (household survey) when attempting to discern current economic conditions. However, results from the pseudo out-of-sample forecasting exercise presented in this paper suggest that analysts question whether employment is a useful predictor of output growth over a one-quarter horizon.

\section{REFERENCES}

Aaronson, Daniel; Rissman, Ellen R. and Sullivan, Daniel G. "Can Sectoral Reallocation Explain the Jobless Recovery?" Federal Reserve Bank of Chicago Economic Perspectives, Second Quarter 2004, 28(2), pp. 36-49.

Ahmed, Shaghil; Levin, Andrew and Wilson, Beth Anne. "Recent U.S. Macroeconomic Stability: Good Policies, Good Practices, or Good Luck?" Review of Economics and Statistics, August 2004, 86(3), pp. 824-32.

Bernanke, Ben S. “The Jobless Recovery.” Presented at the Carnegie Mellon University conference Global Economic and Investment Outlook, Pittsburgh, Pennsylvania, November 6, 2003.

Bowler, Mary and Morisi, Teresa L. "Understanding the Employment Measures from the CPS and CES Survey." Monthly Labor Review, February 2006, 129(2), pp. 23-38; www.bls.gov/opub/mlr/2006/02/ art2full.pdf.

Bowler, Mary; Ilg, Randy E.; Miller, Stephen; Robison, Ed and Polivka. Anne. "Revisions to the Current Population Survey Effective in January 2003.” Bureau of Labor Statistics, February 2003; www.bls.gov/cps/rvcps03.pdf.

Clark, Todd E. and McCracken, Michael W. "Evaluating Direct Multistep Forecasts.” Econometric Reviews, October 2005, 24(4), pp. 369-404.

Clark, Todd E. and McCracken, Michael W. "Tests of Equal Forecast Accuracy and Encompassing for Nested Models." Journal of Econometrics, November 2001, 105(1), pp. 85-110. 
Diebold, Francis X. and Mariano, Roberto S. "Comparing Predictive Accuracy." Journal of Business and Economic Statistics, July 1995, 13(3), pp. 253-63.

Groshen, Erica L. and Potter, Simon M. "Has Structural Change Contributed to the Jobless Recovery?" Federal Reserve Bank of New York Current Issues in Economics and Finance, August 2003, $9(8)$.

Juhn, Chinhui and Potter, Simon M. "Explaining the Recent Divergence in Payroll and Household Employment Growth.” Federal Reserve Bank of New York Current Issues in Economics and Finance, December 1999, 5(16).

Kahn, George A. "Sluggish Job Growth: Is Rising Productivity or an Anemic Recovery To Blame?" Federal Reserve Bank of Kansas City Economic Review, Third Quarter 1993, 73(3), pp. 5-25.

Kliesen, Kevin L. and Schmid, Frank A. "Macroeconomic News and Real Interest Rates." Federal Reserve Bank of St. Louis Review, March/ April 2006, 88(2), pp. 133-44.

Kliesen, Kevin L. and Schmid, Frank A. "Monetary Policy Actions, Macroeconomic Data Releases, and Inflation Expectations." Federal Reserve Bank of St. Louis Review, May/June 2004, 86(3), pp. 9-21.

Koenders, Kathryn and Rogerson, Richard. "Organizational Dynamics Over the Business Cycle: A View on Jobless Recoveries.” Federal Reserve Bank of St. Louis Review, July/August 2005, 87(4), pp. 555-79.

McConnell, Margaret M. and Pérez-Quirós, Gabriel. "Output Fluctuations in the United States: What Has Changed since the Early 1980's?” American Economic Review, December 2000, 90(5), pp. 1464-76.

McGuckin, Robert H.; Ozyildirim, Ataman and Zarnowitz, Victor. “A More Timely and Useful Index of Leading Indicators.” Journal of Business and Economic Statistics, January 2007, 25(1), pp. 110-20.
Meese, Richard A. and Rogoff, Kenneth S. "Empirical Exchange Rate Models of the Seventies: Do They Fit Out of Sample?" Journal of International Economics, February 1983, 14(1-2), pp. 3-24.

Nardone, Thomas; Bowler, Mary; Kropf, Jurgen; Kirkland, Katie and Wetrogan, Signe. "Examining the Discrepancy in Employment Growth between the CPS and the CES." Prepared for the Federal Economic Statistics Advisory Committee, October 17, 2003.

Perry, George L. "Gauging Employment: Is the Professional Wisdom Wrong?” Brookings Papers on Economic Activity, 2005, (2), pp. 285-311.

Poole, William. “Data Dependence.” Presented at the Middle Tennessee State University Annual Economic Outlook Conference, Murfreesboro, Tennessee, September 29, 2006.

Polivka, Anne E. and Miller, Stephen M. "The CPS after the Redesign: Refocusing the Economic Lens," in John Haltiwanger, Marilyn E. Manser, and Robert Topel, eds., Labor Statistics Measurement Issues: Studies in Income and Wealth. Volume 60. Chicago: University of Chicago Press, 1998, pp. 249-86.

Schreft, Stacey L. and Singh, Aarti. “A Closer Look at Jobless Recoveries.” Federal Reserve Bank of Kansas City Economic Review, Second Quarter 2003, 80(2), pp. 45-73.

Stock, James H. and Watson, Mark W. "Has Inflation Become Harder to Forecast." Prepared for the Board of Governors of the Federal Reserve System conference Quantitative Evidence on Price Determination, Washington, DC, September 29-30, 2005.

Stock, James H. and Watson, Mark W. "Forecasting Output and Inflation: The Role of Asset Prices." Journal of Economic Literature, September 2003, 41(3), pp. 788-829. 